\title{
NASA'S SNOWEX CAMPAIGN: OBSERVING SEASONAL SNOW IN A FORESTED ENVIRONMENT
}

\author{
Edward Kim ${ }^{1}$, Charles Gatebe ${ }^{1,2}$, Dorothy Hall ${ }^{1,4}$, Jerry Newlin' ${ }^{4}$, Amy Misakonis ${ }^{3}$, Kelly Elder ${ }^{5}$, Hans \\ Peter Marshall ${ }^{6}$, Chris Hiemstra ${ }^{7}$, Ludovic Brucker $^{1,2}$, Eugenia De Marco ${ }^{1,4}$, Chris Crawford ${ }^{9}$, Do \\ Hyuk Kang ${ }^{1,8}$, Jared Entin ${ }^{10}$
}
${ }^{1}$ NASA Goddard Space Flight Center, ${ }^{2}$ USRA,${ }^{3}$ Aerospace Corp.,${ }^{4}$ ATA Aerospace, ${ }^{5}$ US Forest Service, ${ }^{6}$ Boise State Univ., ${ }^{7}$ USACE/CRREL, ${ }^{8}$ Univ. of Maryland, ${ }^{9}$ USGS, ${ }^{10}$ NASA Headquarters

\begin{abstract}
SnowEx is a multi-year airborne snow campaign with the primary goal of addressing the question: How much water is stored in Earth's terrestrial snow-covered regions? Year 1 (2016-17) focused on the distribution of snow-water equivalent (SWE) and the snow energy balance in a forested environment. The year 1 primary site was Grand Mesa and the secondary site was the Senator Beck Basin, both in western, Colorado, USA. Nine sensors on five aircraft made observations using a broad range of sensing techniques-active and passive microwave, and active and passive optical/infrared - to determine the sensitivity and accuracy of these potential satellite remote sensing techniques, along with models, to measure snow under a range of forest conditions. SnowEx also included an extensive range of ground truth measurements - in-situ manual samples, snow pits, ground based remote sensing measurements, and sophisticated new techniques. A detailed description of the data collected will be given and some preliminary results will be presented.
\end{abstract}

Index Terms - snow, cryosphere, field experiment, remote sensing, forest

\section{INTRODUCTION}

Seasonal snow cover is the largest single component of the cryosphere in areal extent (covering an average of $46 \mathrm{M} \mathrm{km}^{2}$ of Earth's surface (31\% of land areas) each year [1]). This seasonal snow has major global societal impacts in the areas of water resources, natural hazards (floods and droughts), water security, and weather and climate. The only practical way to estimate the quantity of snow on a consistent global basis is through satellite remote sensing. Yet, current spacebased techniques underestimate storage of snow water equivalent (SWE) by as much as $50 \%$, and model-based estimates can differ greatly vs. estimates based mainly on remotely-sensed observations. The errors are likely to be greater in the boreal forest and other densely-forested areas around the globe, with the boreal forest being the largest land biome on Earth [2]. At peak coverage, as much as half of snow-covered terrestrial areas involve forested areas, so quantifying the challenge represented by forests is an important part of characterizing the expected performance of any future satellite snow mission.

\section{THE NEED FOR MULTI-SENSOR FIELD OBSERVATIONS}

While there are existing global snow products - such as GlobSnow [3]--that use multi-sensor satellite observations combined with models, the set of available sensors - none of which was designed to focus on snow-limits retrieval accuracy for a notoriously variable target like snow.

Most other past efforts at satellite snow retrievals, and unsuccessful proposed snow satellites, concentrated on a single type of sensor [4]. This single-sensor approach may work for certain snow types and to a limited extent with confounding factors, but not for other places, times, or conditions. Snow simply varies too much.

Due to these and other considerations, such as the microwave capability (and lidar's inability) to pass through clouds, and limitations of microwave techniques (and lidar's capabilities) under wet snow conditions, the snow community consensus is that a multi-sensor approach is needed to adequately address global snow, combined with modeling and data assimilation. What remains at issue, then, is how best to combine and use the various sensors in an optimal way for a global snow satellite mission. That requires a careful and well thought-out effort to collect field measurements that will allow the various tradeoffs to be understood. NASA's SnowEx program is designed to provide algorithm development and risk reduction opportunities for these various snow remote sensing and modeling techniques, including new ones developed since the last large snow campaign of this type, the 2002-03 Cold Land Processes Experiment (CLPX-1) [5]. 
Another expected feature of a future snow mission is the leveraging of sensors on other satellites, both to enhance coverage and accuracy as well as to minimize cost. Since the mix of available sensors-of-opportunity is dynamic, the need for a multi-sensor baseline field dataset with highquality ground truth is essential for quantifying the performance of global snow retrieval in various scenarios of sensor combinations as well as sensor + model scenarios.

\section{SENSORS AND AIRCRAFT}

The original list of core sensors is as follows. All are from NASA unless otherwise noted.

- Radar (volume scattering): European Space Agency's SnowSAR, operated by MetaSensing

- Lidar \& hyperspectral imager: Airborne Snow Observatory (ASO)

- Passive microwave: Airborne Earth Science Microwave Imaging Radiometer (AESMIR)

- Bi-directional Reflectance Function (BRDF): the Cloud Absorption Radiometer (CAR)

- Thermal Infrared imager

- Thermal infrared non-imager from U. Washington

- Video camera

The ASO suite flew on a King Air, and the other sensors flew on a Navy P-3. Unfortunately, AESMIR did not fly.

Two NASA radars flew on G-III aircraft to test more experimental retrieval techniques:

- Radar phase delay: Uninhabited Aerial Vehicle Synthetic Aperture Radar, (UAVSAR)

- InSAR altimetry: Glacier and Ice Surface Topography Interferometer (GLISTIN-A)

And, the prototype Wideband Instrument for Snow Measurements (WISM, Harris Corp. \& NASA) overflew the Grand Mesa with passive and active microwave sensors.

\section{YEAR 1 SITES AND TIMING}

Figure 1 shows a view of the primary Grand Mesa, Colorado site. The Mesa is effectively the green-colored area, and rises $1.7 \mathrm{~km}$ up from the surrounding region to an elevation of $3.4 \mathrm{~km}$ above sea level. Darker greens indicated forested locations. Lighter greens are areas with shorter vegetation. The large black rectangle is a $9.25 \times 32 \mathrm{~km}$ target area imaged by all the airborne sensors. There is a natural gradient of SWE increasing from west (left) to east (right) as well as natural variation in forest cover. The mostly-flat terrain allowed Year 1 of SnowEx to focus on one confounding factor (forest) without the added complication of another (complex terrain).

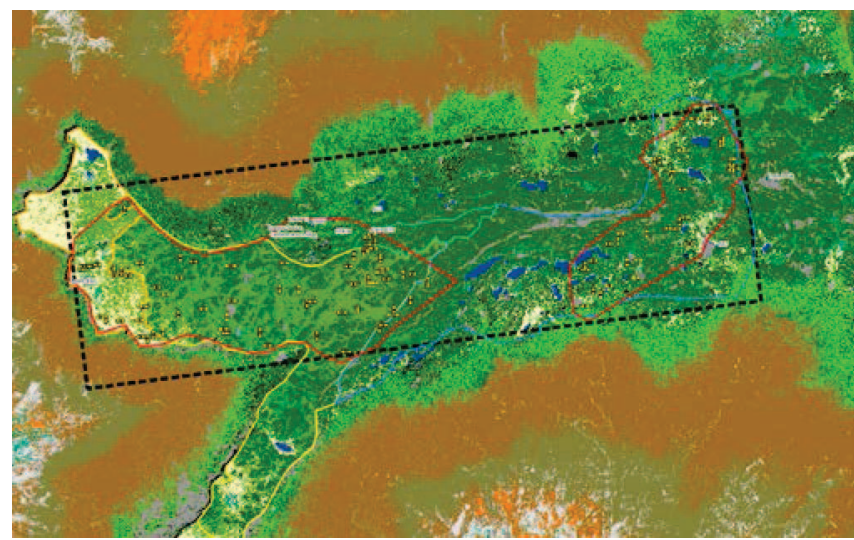

Figure 1. View of primary SnowEx Year 1 site: Grand Mesa, Colorado.

To address certain hydrologic questions, requiring a gauged basin, the secondary site at Senator Beck Basin, Colorado was added. This site began to introduce complex terrain into the mix as well.

Five meteorological stations operated in Grand Mesa and two in Senator Beck to provide supporting information on conditions.

The main winter campaign took place February 5-26, 2017. No-snow ASO lidar and GLISTIN-A altimetry background observations were acquired in late September, 2016. No-snow background SnowSAR data is currently scheduled for September, 2017.

\section{GROUND TRUTH}

Extensive detailed in situ ground truth measurements were collected, including both traditional techniques as well as newer "high-tech" techniques. A partial list of measurements include snow depth, density, temperature, and grain size/type profiles, snow casts, stratigraphy, tree motion, spectral radiance profiles, active and passive microwave signatures, precipitation (including high-speed movies), specific surface area, micropentrometer measurements, terrestrial lidar scans, solar photometry, and time-lapse cameras.

All SnowEx data will be freely accessible to the public. The final archived versions of data will reside at the National Snow and Ice Data Center (NSIDC).

\section{REFERENCES}

[1] Coble, C.R.; E.G. Murray, and D.R. Rice, Earth Science. Englewood Cliffs, NJ: Prentice-Hall, 1987.

[2] "Taiga biological station: FAQ". Wilds.mb.ca. Retrieved 2011$02-21$. 
[3] Luojus, K., et al, GlobSnow-2 Final Report, ESA study contract report ESERIN contract 21703/08/I-EC, October 28, 2014.

[4] H. Rott, et al, " CoRe-H2O - A dual frequency SAR mission for hydrology and climate research, " Proc. IGARSS 2007.

[5] D. Cline, S. Yueh, B. Chapman, B. Stankov, A. Gasiewski, D. Masters, K. Elder, R. Kelly, T.H. Painter, S. Miller, S. Katzberg, and L. Mahrt, 2009: NASA Cold Land Processes Experiment (CLPX 2002/03): Airborne Remote Sensing. J. Hydrometeor, 10, 338-346. 